\title{
Bir Üniversite Öğrenci Yemekhanesinde Simülasyon Modeli Uygulaması $^{1}$
}

\author{
Emre ASLAN \\ Dr. Öğr. Üyesi, Tokat Gaziosmanpaşa Üniversitesi, \\ İktisadi ve İdari Bilimler Fakültesi, İşletme Bölümü \\ emre.aslan@gop.edu.tr \\ Orcid ID: https://orcid.org/0000-0002-1744-8077 \\ Nermin ÖZDERİR \\ Ankara Emniyet Müdürlüğü, Çevik Kuvvet Şube Müdürlüğü \\ nermin.ozdemir@outlook.com \\ Orcid ID: https://orcid.org/0000-0003-0409-617X
}

\begin{abstract}
Öz
Günlük hayatta sıra beklemek, oluşan müşteri kitlesine anında hizmet verememekten kaynaklanmaktadır. Beklemek müşterilerde memnuniyetsizliğe sebep olur, bu nedenle bekleme sürelerini dolayısıyla da memnuniyetsizliği azaltmak için hizmet sistemleri üzerinde çalışılması gerekmektedir. Beklemelerin en çok görüldüğü yerlerden bir tanesi de yemekhanelerdir. Özellikle üniversitelerde öğlen saatlerinde kısıtlı bir zaman diliminde çok sayıda öğrencinin yemekhaneden hizmet almak istemesi sonucunda uzun kuyruklar oluşabilmektedir. $\mathrm{Bu}$ çalışmada öğlen saatlerinde uzun kuyrukların gözlemlendiği bir üniversite öğrenci yemekhanesi için Arena simülasyon yazılımında mevcut durum için model kurulmuş, mevcut durum incelenerek beklemeleri azaltacak alternatif senaryolar geliştirilip denenmiştir. Yoğun bir günde öğrenciler sistemde 40 dakika geçirmekte ve bunun 17 dakikası beklemekle geçmektedir. Alternatif senaryolar ile bu durumun iyileştirilerek sistemde geçirilen sürenin 24 dakikaya, bekleme süresinin ise 1 dakikanın altına indirilebileceği tespit edilmiştir.
\end{abstract}

Anahtar Kelimeler: Simülasyon, Hizmet Sistemleri, Öğrenci Yemekhanesi.

\footnotetext{
${ }^{1}$ Makale Geliş/Kabul Tarihi: 06.10.2019 / 11.07.2021

Künye Bilgisi: Aslan, E. ve Özderir, N. (2021). Bir üniversite öğrenci yemekhanesinde simülasyon uygulaması. Kahramanmaraş Sütçü Imam Üniversitesi Sosyal Bilimler Dergisi, 18(2), 965-978. DOI: 10.33437/ksusbd.629888.
} 


\title{
Simulation Model Application In A University Student Refectory
}

\begin{abstract}
The reason for waiting in the daily life is due to the inability to provide instant service to the customer. Waiting leads to dissatisfaction with customers, so it is necessary to work on service systems for reducing waiting times. One of the places where waiting is observed most is the refectory. Especially in universities, long queues may occur as a result of the large number of students willing to get service from the refectory in a limited time period. In this study, a model was established for the current situation in Arena simulation software for a university student refectory where long queues were observed at noon hours, current model examined and the alternative scenarios that would reduce waiting time were developed and tested. On a busy day, students spend 40 minutes in the system and 17 minutes of it passes by waiting. It was determined that the time spent in the system can be reduced to 24 minutes and the waiting time below 1 minute by improving this situation with alternative scenarios.
\end{abstract}

Keywords: Simulation, Service Systems, Student Refectory.

\section{GİRIŞ}

Sıra beklemek; insanların, makinelerin, araçların günlük hayatta yaptığı rutin işlerdir. Örneğin; havaalanlarına inen ve kalkan uçakların beklemeleri, marketlerde alışveriş sonrası kasiyere hesabı ödemek için oluşan müşteri kuyruğu, maça gitmek isteyen kişilerin oluşturduğu bilet kuyrukları, çeşitli işletmelerin telefon hizmetlerinde sırada bekleyen müşteriler, hastanelerde muayene sırası bekleyen kişiler, bankalarda vezne önünde işlemlerinin yapılmasını bekleyen müşteri kuyruğu, üniversitelerde öğrencilerin oluşturduğu yemek kuyrukları ve endüstriyel üretim alanında faaliyette bulunan işletmelerde montaj için sırada bekleyen parçalar, arızalı makinelerin onarım beklemesi. Bunlar gibi nice örnek hayatın her alanında beklemenin olduğunu göstermektedir. $\mathrm{Bu}$ beklemeler oluşan müşteri kitlesine anında hizmet verememekten kaynaklanmaktadır. Beklemek müssterilerde memnuniyetsizliğe sebep olmakta ve bu memnuniyetsizliği ortadan kaldırmak için çeşitli yollar aranmaktadır.

Sıra beklemelerin oluştuğu hizmet işletmelerinde, hizmet taleplerinin belirsiz olmasından dolayı iki zıt durum ortaya çıkmaktadır. Birincisi, müşterilerin beklemesi ya da beklemelerinden dolayı müşteri kaybı, ikincisi ise hizmet biriminin boş beklemesidir. $\mathrm{Bu}$ sorunların bilimsel teknikler kullanılarak araştırılması zorunlu hale gelmektedir (Çevik ve Yazgan, 2008). 
Özellikle üniversite yemekhanelerinde öğlen saatlerinde yemek kuyruğu fazlasıyla yoğun olmaktadır. Bu yoğunluğun sebepleri ve nasıl azaltılabileceği sistem üzerinde doğrudan denemeler yapmak suretiyle tespit edilebilir. Ancak bu zaman alıcı ve maliyetli olacaktır. Bunun yerine sistemin bir simülasyon modeli kurulup varlıklar ve kaynakların özellikleri (örneğin turnike sayısı, masa/sandalye sayısı, görevli personel sayısı, öğrencilerin dağılımı) dikkate alınarak yoğunluğun sebepleri tespit edilebilir ve yoğunluğu azaltabilecek alternatif senaryolar geliştirilebilir. Böyle bir model üzerinde denemeler neredeyse maliyetsiz ve çok daha kısa sürede yapılabilir.

Bu çalışmanın amacı bir üniversite yemekhanesindeki yoğunluğa simülasyon modeli ile çözüm önerisinde bulunmaktır. Çalışma kapsamında yetkili makamlardan bir üniversitenin merkez yemekhanesinin 1 yıllık kullanım verileri, turnikelerden geçiş zamanları, turnike sayısı, yemekhane kapasitesi gibi gerekli bilgiler temin edilip Arena Simülasyon programı kullanılarak mevcut durumu temsil eden bir simülasyon modeli oluşturulmuş, mevcut modelin geçerliliği test edilip alternatif senaryolar denenmiştir.

Çalışmanın bundan sonraki bölümleri şu şekilde sıralanmıştır. Birinci bölümde simülasyon ve hizmet sistemlerinde uygulamaları üzerine literatürden bahsedilmektedir. İkinci bölümde uygulamanın yapıldığ yer ve toplanan veriler hakkında bilgiler verilmiştir. Üçüncü bölümde mevcut durum ve alternatif senaryolar için simülasyon sonucunda elde edilen bulgular paylaşılmıştır. Sonuç bölümünde ise yemekhane ile ilgili önerilerde bulunulmuştur.

\section{SİMÜLASYON}

\section{Kavramsal Çerçeve}

Genellikle bir bilgisayar uygun bir yazılımı aracılığıyla gerçek sistemlerin davranışını taklit eden yöntem ve uygulamalar topluluğunun genel ismi (Kelton vd., 2006: 1) olarak kullanılan simülasyon (benzetim) hakkında pek çok tanım yapılmıştır. Bunlardan birkaçı;

- Rastgele olmayan (deteminisik) bir bağlantı ile tanımlanamayan problemlerin çözümünde kullanılan bir yöntemdir. Herhangi bir problemi ele alarak bu problemin modelini kurmak ve model üzerinde çeşitli denemeler yaparak bu denemeleri yönetmeyi içermektedir (Arpacı, 1995).

- Bir sistemin belirli bir zaman aralığında ve çalışma koşullarındaki işleyişinin tahmin edilmesi ve incelenmesi amaciyla sistemin bilgisayar modelini kullanan bir analiz aracidır ( Law ve Kelton, 2007). 
- Kullanım alanlarının yaygın olması bakımından son yıllarda kullanılan en güçlü sistem analiz araçlarından biridir. Simülasyon, gerçek sistemin zaman içerindeki davranışını, çok kısa bir sürede taklit etmektedir. Simülasyon gerçeğin belirli bir bölümünün görüntüsünü gösteren bir süreçtir. Daha işlevsel bakıldığında simülasyon, herhangi bir işletmenin veya bir ekonomik yapının ya da bunların alt birimlerinin uzun dönemde davranışlarını tanımlayan matematiksel veya mantıksal modellerle bilgisayarda test edilen sayısal bir yöntemdir (Şahin, 1978).

- Model kurma ve modelin analitik olarak kullanımı sürecidir (Halaç, 1993).

Simülasyon modelleri zamanın rolü olup olmamasına göre statik veya dinamik; sistemin durumunun zaman içindeki değişimine göre sürekli veya kesikli, rassal girdi olup olmamasına göre deterministik veya stokastik olarak sinıflandırılırlar. Simülasyon modelleri el ile, elektronik tablolar ile, genel amaçlı programlama yazılımları ile veya simülasyona özel yazılımlar ile çalıştırılabilirler (Kelton vd., 2006: 8-10).

Bir simülasyon çalışmasının adımları aşağıdaki gibi sıralanabilir (Laughery vd., 1998: 631-633):

- İlgilenilen sistem performans ölçüsünü tanımlama

- Performansı ölçerken değişkenlik gösteren sistem karakteristiklerini tanımlama

- Modelin kapsamını tanımlama

- Süreç akış diyagramlarını geliştirme

- Süreçten veri toplama

- Kaynakları, varlıkları ve özellikleri içeren temel süreç modelini oluşturma

- Temel modelin geçerliliğini gösterme

- Parametrik çalışmaları yürütme

\section{Literatür}

Yemekhane, kafe, restoran vb. hizmet sistemlerinde bekleme hattı ve simülasyon uygulaması üzerine ulaşılabilen sınırlı sayıda çalışmaya aşağıda yer verilmiştir.

Kharwat (1991) hızlı yiyecek endüstrisinde bir pizzacıda simülasyon kullanımı ile imalat ve hizmet kısmının ve teslimat biriminin eleman sayısı, ekipman yerleşimi, iş akışı, müşteri hizmeti ve kapasite iyileştirilmesi üzerine çalışma yapmıştır. Chou ve Liu (1999) bir hızlı yiyecek restoranının simülasyon modelini geliştirerek, yoğun saatlerde müşterilerin bekleme sürelerini azaltacak çözüm önermişlerdir. Church ve Newman (2000) hızlı yiyecek hizmetlerinin teslimatında maliyet-etkin şekilde hizmet hızını maksimize etmek için bilgisayar 
simülasyonu kullanmanın gerekliliği üzerine bir çalışma yapmışlardır. Curin vd. (2005) bir üniversite kampüsünde hızlı yiyecek restoranında hizmet zamanını azaltmak için simülasyon kullanmışlardır. Müşterilerin bekleme sürelerini azaltmak, böylece daha çok müşteriye hizmet edebilmek için kasiyer ve garson sayısını tespit etmişlerdir. Uyrun ve Yıldız (2015) çalışmalarında bir hızlı yiyecek servis sistemini bekleme hattı modeli ile analiz ederek alternatifler üretmişlerdir.

Lee ve Lambert (2006) bir kafeteryada bekleme zamanını azaltmak için simülasyondan yararlanmışlardır. Ek çalışanlar ve farklı bekleme zamanı stratejileriyle bekleme zamanını azaltan önerilerde bulunmuşlardır. Adi ve Dharmawirya (2011) çalışmalarında restoranlarda müşteri beklemelerini azaltmak için kuyruk modelleri kullanılmasının faydalı olacağını ifade etmektedirler. Muslu vd. (2014) bir restoranda bekleme maliyetini belirleyebilmek amacıyla simülasyon uygulaması yapmışlardır. He ve $\mathrm{Hu}$ (2018) simülasyon modeli aracılığıla bir restoranın verilerini kullanarak hizmet kabiliyetini ölçmeyi, ihtiyaç fazlası veya yetersizlik olup olmadığını tespit etmeyi amaçlayan bir çalışma yapmışlardır. Yoğun saatlerde kaynak tahsisini daha etkin olan, geliri arttırıcı, müşterilerin ortalama bekleme süresini azalıp müşteri memnuniyetini arttıran önerilerde bulunmuşlardır. Lee vd. (2019) yiyecek içecek hizmet endüstrisinde merkezi bulaşık yıkama tesisinde işgücü kullanım oranını arttırmak için bir kesikli olay simülasyonu modeli geliştirmişlerdir.

Nettles ve Gregoire (1997) bir ilkokul yemekhanesinde çalışanlar ve sınıfların geliş zamanlarındaki değişikliğin etkisini inceleme amacıyla bilgisayar simülasyonu kullanmışlardır. Bir elemanı biten yemekleri tamamlamak için dağıtıcı olarak kullanmanın ve sınıfların geliş saatlerini düzenlemenin bekleme süresini azalttığını tespit etmişlerdir. Yıldız ve Arslan (2013) bir üniversite merkez yemekhanesinde, öğrencilerin yemek kuyruğunda oluşan beklemelere ilişkin durumları incelenerek beklemeleri en aza düşürmek, personel çalışmalarını en etkin kullanmak amacıyla bekleme hattı ile bir çalışma yapılmışlardır. Yoğun saatlere çözüm olması için personel ve turnike açısından önerilerde bulunmuşlardır.

Bunlar haricinde hizmet sistemlerinde simülasyon uygulaması üzerine ulaşılabilen çalışmalar aşağıda özetlenmiştir.

Gupta ve Williams (2004) bir otomobil servis atölyesinde; Özdağoğlu vd. (2009) bir araştırma ve uygulama hastanesinin acil servis bölümünde; Sinreich ve Marmor (2005) bir hastanenin acil servisinde; Akdeniz ve Tatar (2009) bir havaalanında gelen giden uçakların bekleme optimizasyonunu sağlamak ve duruma göre havaalanında yeni bir piste ihtiyaç duyulup duyulmayacağ 1 araştırmak üzere; Koruca vd. (2011) bir ilin elektrik arıza birimine bildirilen arızaların beklemesini azaltmak ve personel kullanım oranlarını artırmak için; 
Tan vd. (2013) hizmet işletmelerinde süreç simülasyonu için bir çerçeve geliştirmişlerdir. Söyler ve Koç (2014) bir kamu hastanesinin acil servis bölümünü değerlendirerek hastaların sistemde kalma sürelerini azaltma, birim zamanda hizmet verilen hasta sayısını artırma ve eldeki kaynakları etkin şekilde kullanımı sağlamak amacıyla simülasyon uygulaması yapmışlardır.

\section{UYGULAMANIN METODOLOJISI}

\section{Uygulamanın Amacı ve Önemi}

$\mathrm{Bu}$ çalışmanın bir üniversite yemekhanesinde yoğun saatlerde uzun süre bekleme problemine çözüm bulmaktır. Bu amaçla yemekhanenin mevcut durumuna ilişkin gerekli veriler toplanarak simülasyon modeli kurulmuş, modelin geçerliliği sağlandıktan sonra bekleme süresini kısaltabilecek alternatif senaryolar model üzerinde denenmiştir.

Hizmet sistemlerinde bekleme süresinin uzaması hizmet alan kişilerde memnuniyetsizliğe neden olmaktadır. Bir üniversite yemekhanesinde de öğrencilerin büyük çoğunluğunun yemek için sınırlı bir zamanı olduğu dikkate alınırsa, yoğun saatlerde bekleme sürelerini kısaltacak çözümler bulmanın önemli olduğu anlaşılır.

\section{Uygulamanın Kapsamı}

$\mathrm{Bu}$ çalı̧̧madaki uygulama bir üniversitenin öğrenci yemekhanesinde yapılmıştır. Uygulamanın yapıldığı yemekhanenin bulunduğu üniversitenin kampüsünde bulunan enstitü, fakülte ve yüksekokullarda 2018-2019 Öğretim yılı (15.10.2018) tarihi itibariyle 35000 öğrenci öğrenim görmektedir.

Üniversitenin kampüsünde 2 adet yemekhane binası vardır, bu yemekhanelerde hem idari ve akademik personel hem de öğrenciler yemek yemektedirler. İdari ve akademik personelin yemek yedikleri bölümlerde öğlen saatlerinde dahi dikkate değer bir yoğunluk gözlemlenmemesine rağmen, öğrencilerin yemek yediği bölümlerde her iki yemekhanede de özellikle öğlen saatlerinde yoğunluk ve uzun kuyruklar oluştuğu gözlemlenmektedir. Merkezi yemekhane merkezi bir yerde olduğu için genellikle daha yoğun olmaktadır. $\mathrm{Bu}$ nedenle uygulamanın yapılacağı yer merkez yemekhanesindeki öğrenci bölümü olarak belirlenmiştir.

\section{Uygulamanın Yöntemi}

$\mathrm{Bu}$ çalışmadaki uygulama örnek olay analizi şeklinde yapılmıştır. Öğrencilerin yemekhane kullanım verileri izin alınarak Sağlık Kültür Spor Daire Başkanlığından, diğer gerekli bilgiler üniversite web sayfası, yemekhanede ilgili 
görevlilerle mülakat ve gözlem yoluyla elde edilmiştir. Araştırmanın amacı olan yoğun saatlerde öğrencilerin bekleme sürelerini azaltmak için elde edilen verilerle Arena simülasyon yazılımında sistemin simülasyon modeli kurulmuş, geçerliliği tespit edildikten sonra denemeler yapılmıştır.

\section{Mevcut Durum Analizi}

Şekil 1'de görüleceği üzere merkez yemekhanede öğrencilerin yemek yediği 2 ayrı salonunda 100'er masa 400'er sandalye olmak üzere toplam 200 masa 800 sandalye bulunmaktadır. Her salonda 2 adet turnike ve yemek alınacak yerler vardır. Ayrıca gereken durumlarda 56 masa 224 sandalye ek olarak hizmete sunulabilmektedir.

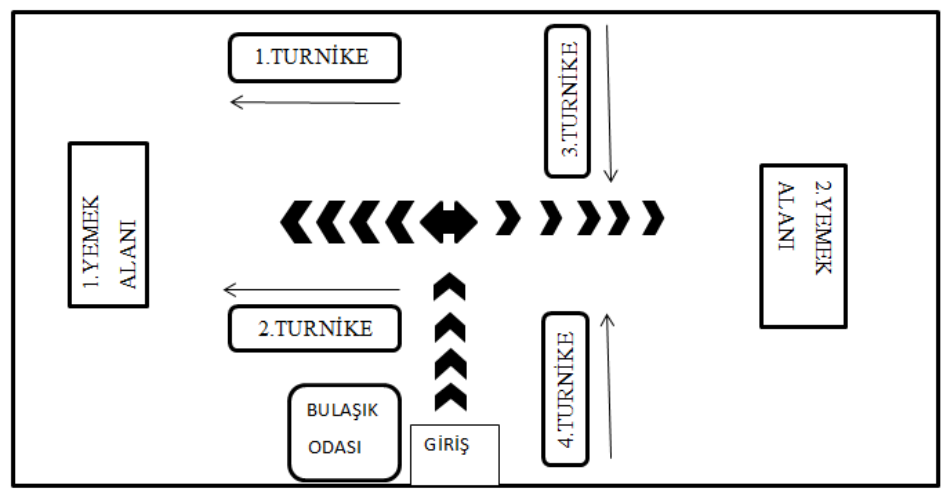

Şekil 1. Yemekhane Yerleşim Planı

Merkez yemekhane hafta sonu ve resmi tatil günleri dişında gün içerisinde 11.00-16.00 saatleri arasında günde 5 saat faaliyet göstermektedir. Merkez yemekhane öğrenci bölümünde 4 turnike bulunmaktadır. Öğrenci gelişlerine göre 2 turnike açılarak hizmet verilmekte, öğrenci sayısının artışı doğrultusunda 3. ve 4. Turnike de hizmete açılmaktadır. 1. ve 2. turnikelerde 4'er, 3. ve 4. turnikelerde ise 3'er aşçı bulunmaktadır. Öğrenciler hizmet almak için kuyruğa girdiklerinde ilk giren ilk hizmet alır servis disiplini ile hizmet almaktadırlar.

Merkez yemekhane verilerine göre 2018 yılında öğrenciler 335.983 defa yemekhaneden hizmet almıştır. 2018 yılında aylık öğrenci verileri Tablo 1'de verilmiştir. Öğrencilerin yemekhaneden en çok hizmet aldığ 1 ay Ekim ayıdır (58.329). Bunun yanında öğrencilerin en az hizmet aldığı ay ise Temmuz ayıdır (2438). Haziran, Temmuz ve Ağustos aylarında tatilden dolay1 yemekhaneden hizmet alan öğrenci sayısı az olmaktadır, bu aylarda yaz okuluna devam eden öğrenciler yemekhaneyi kullanmaktadırlar. 
Tablo 1. 2018 Yılı Aylık Yemekhaneye Gelen Öğrenci Sayıs1

\begin{tabular}{|c|c|c|c|}
\hline Tarih & Öğrenci Sayısı & Tarih & Öğrenci Sayısı \\
\hline Ocak & 18577 & Temmuz & 2438 \\
\hline Şubat & 26277 & Ağustos & 3321 \\
\hline Mart & 52448 & Eylül & 17207 \\
\hline Nisan & 34643 & Ekim & 58329 \\
\hline Mayıs & 32997 & Kasım & 44978 \\
\hline Haziran & 3321 & Aralık & 41449 \\
\hline
\end{tabular}

Merkez yemekhanede 2018 y1lında en çok hizmet alan öğrencinin olduğu ilk 10 gün Tablo 2'de verilmiştir. Salı ve Çarşamba günlerinin diğer günlere göre daha yoğun olduğu görülmektedir, bunun sebebinin haftanın orta günleri olması ve öğrencilerin bu günlerde ders yoğunluğunun fazla olması olduğu söylenebilir. Veriler incelendiğinde en az yoğun olan günlerin Pazartesi ve Cuma günleri olduğu tespit edilmiştir.

Tablo 2. 2018 Yllında Merkez Yemekhanenin En Yoğun Günleri

\begin{tabular}{|l|c|l|c|}
\hline Tarih & Öğrenci Sayısı & Tarih & Öğrenci Sayısı \\
\hline 22 Mart 2018 Salı & 2914 & 11 Ekim 2018 Salı & 3403 \\
\hline $\begin{array}{l}\text { 27 Nisan 2018 } \\
\text { Çarşamba }\end{array}$ & 2680 & 12 Ekim 2018 Çarşamba & 3362 \\
\hline 27 Eylül 2018 Salı & 3364 & 19 Ekim 2018 Çarşamba & 3657 \\
\hline $\begin{array}{l}\text { 28 Eylül 2018 } \\
\text { Çarşamba }\end{array}$ & 3287 & 02 Kasım 2018 Çarşamba & 3330 \\
\hline 04 Ekim 2018 Salı & 3634 & 07 Aralık 2018 Çarşamba & 2968 \\
\hline
\end{tabular}

Turnikelerin kaç tanesinin açılacağına öğrenci geliş yoğunluğuna göre karar verilmektedir. Örnek olarak 2018 Eylül ayında açılan turnike sayıları Tablo 3'te verilmektedir. Eylül ayının ilk günleri sadece bir turnike kullanılırken ay sonuna doğru gelen öğrenci sayısının artmasıyla turnike sayısı dörde çıkmaktadır.

Tablo 3. 2018 Eylül Ayında Kullanılan Turnike Sayıları

\begin{tabular}{|c|c|c|c|}
\hline Tarih & Kullanılan Turnike Sayısı & Tarih & $\begin{array}{c}\text { Kullanılan Turnike } \\
\text { Sayısı }\end{array}$ \\
\hline 02.09 .2018 & 1 & 21.09 .2018 & 2 \\
\hline 05.09 .2018 & 1 & 22.09 .2018 & 2 \\
\hline 06.09 .2018 & 1 & 23.09 .2018 & 1 \\
\hline 07.09 .2018 & 1 & 26.09 .2018 & 4 \\
\hline 08.09 .2018 & 1 & 27.09 .2018 & 4 \\
\hline 09.09 .2018 & 1 & 28.09 .2018 & 4 \\
\hline
\end{tabular}




\begin{tabular}{|l|l|l|l|}
19.09 .2018 & 2 & 29.09 .2018 & 4 \\
\hline 20.09 .2018 & 2 & 30.09 .2018 & 3 \\
\hline
\end{tabular}

$\mathrm{Bu}$ verilerin dışında öğrencilerin girişlerinde turnikede yemek alırken bekledikleri süreler de öğrenci beklemelerini etkilemektedir. Gözlem yolu ile 95 öğrencinin turnikeden yemek alma süreleri kaydedilmiş, Arena Input Analyzer ile $(9,13.6,18)$ üçgensel dağılım gösterdiği belirlenmiştir.

Yemekhanenin mevcut durumunun simülasyon modeli Şekil 2'de görülmektedir.

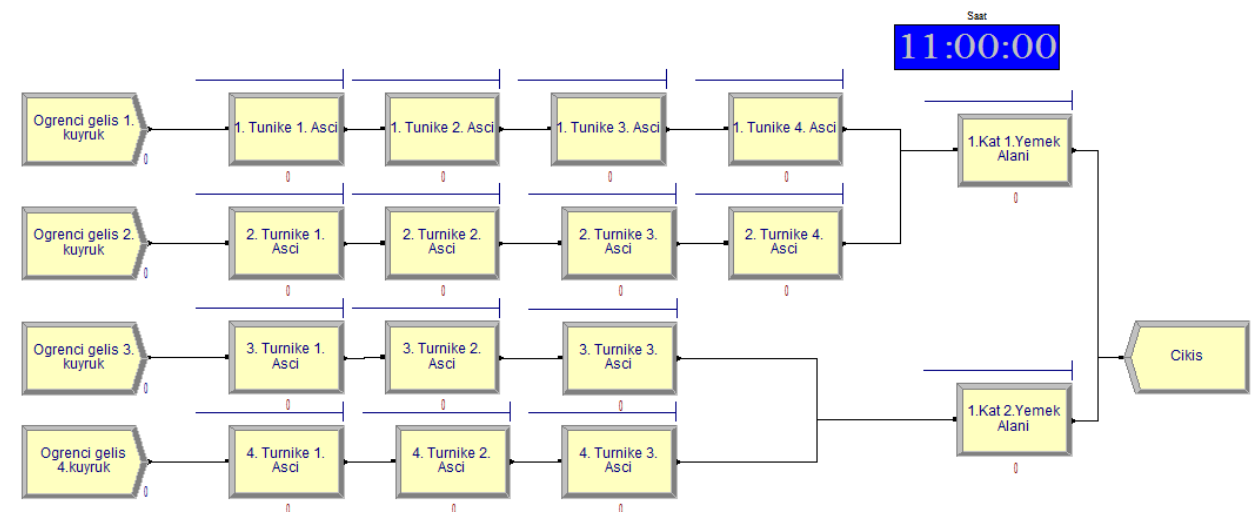

Şekil 2. Yemekhane Mevcut Durum Simülasyon Modeli

Ekim ayında kalabalık bir günde yemekhaneye öğrenci gelişleri 10 dakikalık zaman dilimlerinde incelendiğinde yoğunluğun 11.00-13.00 saatleri arasında olduğu görülmektedir (Şekil 3). Bu çalışmadaki amaç yoğun olan saatlerde öğrencilerin beklemelerine çözüm bulmak olduğu için bu zaman dilimine odaklanılacaktır.

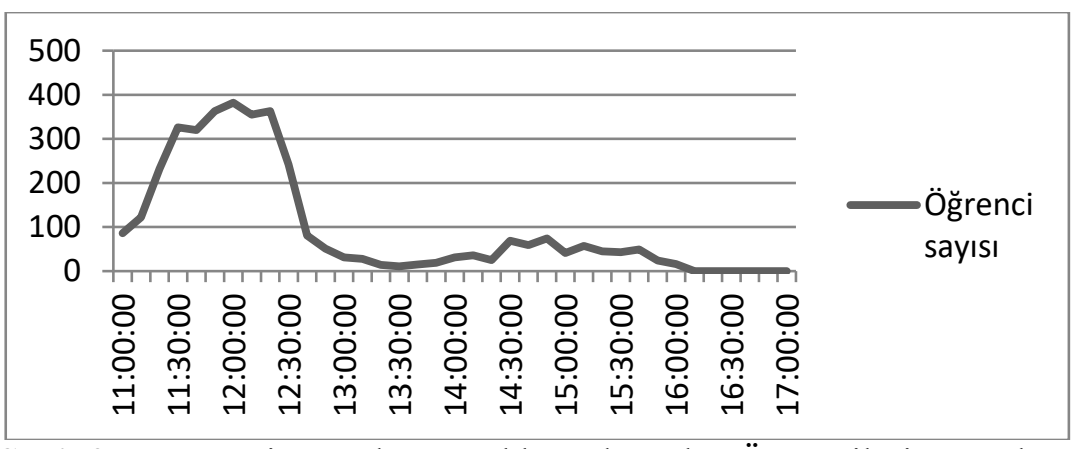

Şekil 3. Yoğun Bir Günde Yemekhanede Gelen Öğrencilerin Dağılımı 
Çalışmanın amacı yoğun günlerde beklemeleri ve hizmet alma sürelerini azaltmak olduğu için en yoğun gün 19.10.2018 günü 11.00-13.00 arası gelişler kullanılarak simülasyon modeli çalıştırılmıştır. Bütün modeller 100 tekrar ile çalıştırılmıştır, elde edilen sonuçlar 100 tekrarın ortalamasıdır. Mevcut durumda sistemden çıkan öğrenci sayısı 2854, ortalama bekleme süresi 17,71 dk., sistemde kalma süresi 40,76 dk. olarak hesaplanmıştır. Gerçek verilerde 11:00-13:00 arasında sisteme giriş yapan öğrenci sayısının 2923 olduğu dikkate alınırsa modelin geçerli olduğu söylenebilir.

\section{Mevcut Duruma Alternatif Senaryolar}

Mevcut durumdaki problemleri çözmek için alternatif senaryolar geliştirilmiştir. Alternatif Senaryo 1'de 11:00-13:00 arasındaki yoğunluğu azaltabilmek için saat 14:00'dan sonra yemek yiyen öğrencilerin kartına 2 puan yüklenmesi, 10 puana ulaştığında da bir gün ücretsiz yeme hakkı kazanacağı bu sayede öğrencilerin \%30'luk bir kısmının yoğun saatler dışına kayacağı varsayılmıştır. Alternatif Senaryo 2'de mevcut durumda 3. ve 4. turnike geç açılması ve bu sırada 1. ve 2. turnikede kuyruk oluşmaya başlamış olması problemine çözüm olarak 3. ve 4. turnikelerin de 11:00'dan itibaren açı olması ve öğrencilerin dengeli şekilde yönlendirilmesi denenmiştir. Alternatif Senaryo 3’te 4 turnikeye ek olarak 5. bir turnike eklenmesi durumu denenmiştir. Mevcut durum ve denenen alternatiflere ait sonuçlar Tablo 4'te görülmektedir.

Tablo 4. Mevcut Durum ve Alternatif Senaryo Karşılaştırması

\begin{tabular}{|l|c|c|c|}
\hline & $\begin{array}{c}\text { Sistemden Çıkan } \\
\text { Öğrenci Sayısı }\end{array}$ & $\begin{array}{c}\text { Bekleme Süresi } \\
\text { (Ortalama) dk. }\end{array}$ & $\begin{array}{c}\text { Toplam Süre } \\
\text { (Ortalama) dk. }\end{array}$ \\
\hline Mevcut Durum & 2854 & 17.71 & 40.77 \\
\hline Alternatif Senaryo 1 & 1982 & 0.11 & 23.45 \\
\hline Alternatif Senaryo 2 & 2670 & 1.92 & 25.27 \\
\hline Alternatif Senaryo 3 & 2869 & 0.71 & 24.01 \\
\hline
\end{tabular}

Tablo 4 incelendiğinde mevcut durumda 2854 öğrenci belirlenen saatlerde yemekhaneden hizmet alabilmektedir. Fakat öğrencilerin ortalama bekleme süresi $17,71 \mathrm{dk}$, bekleme ve ortalama hizmet alma süresi (bekleme süresi + yemek yeme süresi) ortalaması $40,77 \mathrm{dk}$. olmaktadır. Alternatif Senaryo 1'de promosyon uygulaması ile öğrencilerin \%30'luk bir kısmının yoğun olmayan saatlerde hizmet alacağı varsayımı ile gelişler düzenlenmiş ve bu da doğal olarak hizmet alan öğrenci sayısında (1982) yaklaşık \%30'luk bir azalmaya neden olmuştur. Fakat bu sayede ortalama bekleme süresi neredeyse sıfıra $(0,11 \mathrm{dk}$.) yaklaşmış, toplam süre neredeyse yarısına (23,45 dk.) inmiştir. Alternatif Senaryo 2'de 3. ve 4. turnikelerin erken açılması ile mevcut durumdakine yakın sayıda öğrenci (2670) yemekhaneden hizmet alırken ortalama olarak 1,92 dk. beklemekte, 
toplam olarak da 25,27 dk. sistem içinde zaman geçirmektedir. Alternatif Senaryo 3 'te 5. turnikenin eklenmesiyle mevcut durumdakinden biraz fazla (2869) öğrenci ortalama olarak neredeyse hiç bekleme yapmadan $(0,71 \mathrm{dk}$.) toplam olarak 24,01 $\mathrm{dk}$. sistem içinde zaman geçirmektedir.

\section{SONUÇ}

Bekleme, hizmeti sağlayanın meşgul olması nedeniyle o anda oluşan talebe cevap verememesi veya hizmet kapasitesinin talebi karşılayamaması sonucu oluşan tıkanıklıktır. Beklemek müşterilerde memnuniyetsizliğe sebep olduğu için bekleme sürelerini azaltmak için hizmet sistemleri üzerinde çalışılması gerekmektedir.

$\mathrm{Bu}$ çalışmada bir üniversitenin, özellikle öğlen saatlerinde yoğunluğun gözlemlenen, öğrenci yemekhanesinde oluşan yoğunluk ve beklemelere simülasyon ile çözüm bulunmaya çalışılmıştır. Mevcut duruma alternatif olabilecek üç ayrı senaryo denenmiştir. Mevcut durumda öğrenciler yoğun saatlerde ortalama olarak yemek yeme süresi kadar sirada beklemek durumunda kalmaktadırlar. Buna çözüm olarak promosyon ile yoğunluğu azaltmak, öğrencilerin turnikelere dengeli dağılmasını sağlamak ve ek turnike kullanmak alternatifleri denenmiştir. Mevcut durumda ilk iki turnikede sıra oluşmaya başlayınca öğrenciler diğer turnikelere gitmektedir. Öğrencilerin turnikelere dengeli dağılmasını sağlamak (Alternatif Senaryo 2) mevcut durumda ciddi bir değişiklik yapmadan beklemeleri azaltabilecek bir alternatiftir. Bunun haricinde promosyon ile yoğunluğu azaltmak (Alternatif Senaryo 1) doğal olarak yoğun saatlerdeki öğrencilerin bir kısmını yoğun olmayan saatlere kaydırmak suretiyle beklemeleri azaltmaktadır. Ek turnike kullanmak (Alternatif Senaryo 3) ise ek bir kaynak kullanarak aynı yoğunlukta daha az bekleme sürelerini sağlayabilmektedir. Her bir alternatifin sağladığı faydalar ve neden olduğu maliyetler karşılaştırılarak uygun olan seçilebilir.

$\mathrm{Bu}$ çalışmada yoğun saatlere bir çözüm bulunmaya çalışılmıştır, yoğun olmayan saatler, veya yoğun olmayan günler için de kaynakların kullanım oranlarına göre kaynak azaltma yoluna gidilebilir. Talep tahmimi çalışması yaparak mevsim, ay, haftanın günü ve hatta yemek türüne göre talebin ne olacăg 1 tahmin edilerek ona göre kaynak kullanımı üzerine bir çalışma yapılabilir. Turnike verileri öğrencilerin turnikeden geçiş zamanlarını vermekte fakat yemekhane binasına geliş zamanlarını vermemektedir. Bu da yoğunluğun fazla olduğundan dolayı hizmet almayıp geri dönen öğrencilerin göz ardı edilmesine neden olmaktadır. İleride gözlem yoluyla öğrencilerin yemekhane binasına geliş zamanlarını incelemek daha doğru sonuçlar elde etmeye imkan tanıyacaktır. 


\section{KAYNAKLAR}

Adi, E. ve Dharmawirya, M. (2011). Case study for restaurant queuing mode, International Conference on Management and Artificial Intelligence IPEDR, 7, 52-55

Akdeniz, H. A., B. Tatar (2009). Havalimanında kuyruk simülasyonu: İzmirGaziemir Adnan Menderes Havalimanı uygulaması, Dokuz Eylül Üniversitesi Sosyal Bilimler Enstitüsü Dergisi, 11(3), 3-12, İzmir.

Arpacı, S. S. (1995). Konut projelerinde simülasyon yaklaşım ile maliyet tahmini, [Yüksek lisans tezi], İstanbul Teknik Üniversitesi.

Chou, C. Y., and Liu, H. R. (1999). Simulation study on the queuing system in a fast-food restaurant. Journal of Restaurant \& Foodservice Marketing, 3(2), 23-36.

Church, I., and Newman, A. J. (2000). Using simulations in the optimisation of fast food service delivery. British Food Journal, 102(5-6), 398-405.

Curin, S. A., Vosko, J. S., Chan, E. W., and Tsimhoni, O. (2005, December). Reducing service time at a busy fast food restaurant on campus. In Proceedings of the 37th conference on Winter simulation (pp. 26282635). Winter Simulation Conference.

Çevik, Y. ve Yazgan, A. E. (2008), Hizmet üreten bir sistemin bekleme hattı(kuyruk) modeli ile etkinliğinin ölçülmesi, Niğde Üniversitesi İktisadi Ve İdari Bilimler Fakültesi Dergisi, 1(2), 119-128.

Gupta, N., and Williams, E. J. (2004). Simulation improves service and profitability of an automobile service garage. In Proceedings of the 16th European Simulation Symposium.

Halaç, O. (1993), İşletmelerde simülasyon teknikleri, Alfa Basım Yayım.

He, H. and Hu, Z. (2018, July). Analysis of fast food service capability based on flexsim modeling and simulation. In IOP Conference Series: Materials Science and Engineering, 394(5), p. 052005). IOP Publishing.

Kelton, W. D., Sadowski, R. P., and Sturrock, D. T. (2007). Simulation with arena. 4th Ed. McGrawHill.

Koruca, H. İ., Aydemir, E., Oktay, A., ve Uğurlu, N. (2011). Isparta ili elektrik arıza tamir bakım biriminde simülasyon destekli personel planlama ve 
organizasyon yapılandırma araştırması. Süleyman Demirel Üniversitesi Fen Bilimleri Enstitüsü Dergisi, 15(3), 218-223.

Kharwat, A. K. (1991, December). Computer simulation: an important tool in the fast-food industry. In Proceedings of the 23rd conference on Winter simulation (pp. 811-815). IEEE Computer Society.

Laughery, R., Plott, B., and Scott-Nash, S. (1998). Simulation of service systems. Handbook of Simulation, 629-644.

Law, M. A. and Kelton, D. W. (2000), Simulation modeling and analysis, McGraw-Hill, USA.

Lee, K. W., and Lambert, C. U. (2006). Using simulation to manage waiting time in a cafeteria. Information Technology in Hospitality, 4(4), 127-141.

Lee, C. K., Zhang, S., and Ng, K. K. (2019). In-plant logistics simulation model for the catering service industry towards sustainable development: A case study. Sustainability, 11(13), 3655.

Muslu, I., Jakshylykov, J., Soorbekova, B., Kutmanova, U., and Musiralieva, M. (2014). Restaurant process simulation in Kyrgyzstan. In 2014 11th International Conference on Electronics, Computer and Computation (ICECCO) (pp. 1-4). IEEE.

Nettles, M. F., and Gregoire, M. B. (1997). Use of computer simulation in school foodservice. Foodservice Research International, 9(3), 143-156.

Özdağoğlu, A., Yalçınkaya, Ö., ve Özdağoğlu, G. (2009). Ege bölgesi’ndeki bir araştırma ve uygulama hastanesinin acil hasta verilerinin simüle edilerek analizi, İstanbul Ticaret Üniversitesi Fen Bilimleri Dergisi, 8(16), 61-73.

Söyler, H., ve Ali, Koç. (2014). Bir kamu hastanesi için acil servis simülasyonu ve veri zarflama analizi ile etkinlik ölçümü. Aksaray Üniversitesi İktisadi Ve İdari Bilimler Fakültesi Dergisi, 6(2), 115-132.

Şahin, M. (1978), Üretim yönetiminde simülasyon analizi ve uygulamast, Eskişehir İktisadi ve Ticari İlimler Akademisi.

Tan, W., Xu, W., Yang, F., Xu, L., and Jiang, C. (2013). A framework for service enterprise workflow simulation with multi-agents cooperation. Enterprise Information Systems, 7(4), 523-542. 
Uyrun, A. ve Yıldız, M. S. (2015). Hızlı yiyecek içecek işletmesi servis sisteminin bekleme hattı modeliyle analizine yönelik bir uygulama, Atatürk Üniversitesi İktisadi ve İdari Bilimler Dergisi, 29(1), 19-34

Yıldız, M. S. ve Arslan H.M. (2013), Bekleme hattı modeliyle servis sisteminin analizi: düzce üniversitesi merkez yemekhanesi örneği, Yönetim ve Araştırma Dergisi, 21, 169-184. 